\title{
Study of Aetiological and Clinical Profile of Stroke Patients with Special Reference to Baseline Intracranial Haemorrhage Score in Haemorrhagic Stroke in North East India - A Hospital Based Cross-Sectional Study
}

\author{
Balaji Dhanabalan ${ }^{1}$, Anupam Dutta ${ }^{2}$, Ajit Kumar Pegu³ ${ }^{3}$ Bharath H. R ${ }^{4}$ Bhabani Sankar Dhal ${ }^{5}$ \\ 1, 2, 3, 4,5 Department of Medicine, Assam Medical College and Hospital, Dibrugarh, Assam, India.
}

\section{ABSTRACT}

\section{BACKGROUND}

As defined by World Health Organization (WHO), stroke is accountable for 5 million deaths and 5 million disabled patients throughout the world. The prevalence of stroke is in rising trend in Indian subcontinent and therefore is a source of socioeconomic concern. This study was conducted to evaluate the aetiological and clinical profile in stroke patients with special reference to baseline intracranial haemorrhage (ICH) score in haemorrhagic stroke in North East India.

\section{METHODS}

The study was carried out among in-patients of Medicine Department at Assam Medical College and Hospital, Dibrugarh in North East India from March 2019 to February 2020. A total of 112 patients who presented with symptoms suggestive of stroke were assessed. Mean \pm standard deviation was used to express continuous variables. Frequency and percentage were used to express categorical variables. Test of significance for qualitative data was assessed by chi-square test (for $2 \times 2$ tables). P-value less than 0.05 was taken as statistically significant.

\section{RESULTS}

In our study stroke was common in 40 - 60 years age group which comprised $50 \%$ of total patients. Stroke was more common in males with a sex ratio of 1.24:1.73.2 \% of patients suffered haemorrhagic stroke and $22.3 \%$ suffered ischemic stroke whereas $4.5 \%$ suffered cardio-embolic stroke. Hypertension was the most prevalent and an important risk factor with $80.3 \%(\mathrm{P}=0.001)$, followed by smoking with $39 \%$ $(\mathrm{P}=0.021)$, chronic alcohol consumption with $37 \%(\mathrm{P}=0.028)$ and diabetes with 22 $\%$. The most common site of haemorrhage was basal ganglia (28\%) followed by thalamus $(24 \%)$. Patients presenting with intraventricular extension, infratentorial location, low Glasgow Coma Scale (GCS) score $(<4)$ or having high ICH score $(\geq 3)$ at the time of presentation were associated with increased mortality in haemorrhagic stroke $(\mathrm{P}=0.010)$.

\section{CONCLUSIONS}

Haemorrhagic strokes (73.2 \%) are the most common type. Hypertension is the most prevalent and an important risk factor (80.3 \%). Basal ganglia (28\%) are the most common sites involved in haemorrhagic stroke; infratentorial location is associated with poor prognosis. Patients presenting with low GCS score $(<4)$ or having high ICH score $(\geq 3)$ at the time of presentation are associated with increased mortality in haemorrhagic stroke.

\section{KEY WORDS}

Stroke, Hypertension, Basal Ganglia, GCS Score, ICH Score
Corresponding Author: Dr. Balaji Dhanabalan, Department of Medicine, Assam Medical College and Hospital, Dibrugarh, Assam - 786002, India. E-mail: balajidhanabalan@gmail.com

\section{DOI: $10.14260 / j e m d s / 2021 / 204$}

How to Cite This Article:

Dhanabalan B, Dutta A, Pegu AK, et al. Study of aetiological and clinical profile of stroke patients with special reference to baseline intracranial haemorrhage score in haemorrhagic stroke in North East India - a hospital based cross - sectional study. J Evolution Med Dent Sci 2021;10(13):947951, DOI: 10.14260/jemds/2021/204

Submission 08-09-2020,

Peer Review 01-02-2021,

Acceptance 06-02-2021,

Published 29-03-2021.

Copyright (C) 2021 Balaji Dhanabalan et al. This is an open access article distributed under Creative Commons Attribution License [Attribution 4.0 International (CC BY 4.0)] 


\section{BACKGROUND}

Cerebrovascular diseases include some of the most common and devastating disorders like ischemic stroke, haemorrhagic stroke and cardio-embolic stroke. The incidence rises steeply with age, and in many lower- and middle-income countries, it is rising in association with less healthy lifestyles. World Health Organization describes "stroke" as "rapidly evolving clinical signs of focal (or global) disruption of cerebral function with features lasting for not less than 24 hours or causing death, with no obvious source other than vascular origin'. The clinical manifestations of stroke are highly variable because of complex anatomy of the brain and its vasculature. Cerebral ischemia is caused by a reduction in blood flow that lasts longer than several seconds. Neurologic symptoms are manifested within seconds because neurons lack glycogen, so energy failure is rapid. If the cessation of flow lasts for more than a few minutes, infarction or death of brain tissue results. When blood flow is quickly restored, brain tissue can recover fully and the patient's symptoms are only transient: this is called a transient ischemic attack (TIA). Worldwide, nearly 2 crore people suffer from stroke annually; 50 lakh die as a sequelae and 1.5 crore survive; of those, who survive, 50 lakh are disabled. ${ }^{1}$

Lifestyle related factors that increase the risk of stroke such as systemic hypertension, diabetes mellitus, obesity, salt intake etc. have to be managed in an effectual manner like absolute cessation of smoking and alcohol.2 Majority of the stroke risk factors are modifiable. Hence, identification of modifiable risk factor is important to decrease the stroke incidence at primary intervention level. Although, it is not uncommon in younger population, stroke in young adults pose a major socioeconomic health problem especially in developing countries. Stroke is next to ischaemic heart disease as the most frequent cause of death accounting for 6.3 million deaths (11\% of the total) per year. It accounts for more than half of all in-patients admitted in neurology. ${ }^{3}$

Intracranial haemorrhage is caused by bleeding directly into or around the brain; it produces neurologic symptoms by producing a mass effect on neural structures, from the toxic effects of blood itself or by increasing intracranial pressure. Intracranial haemorrhage is quite a serious disease in-spite of attempts aimed at improving outcome by medical and neurosurgical intervention.

Numerous parameters either clinical or neuro-radiological such as age, location, size, volume of haemorrhage, presence / absence of intraventricular extension, hydrocephalous, Glasgow Coma Scale, severity of neurological deficit and others can predict the consequence of ICH. The ICH score is a clinical grading scale consists of five factors such as GCS score, age, ICH volume, intraventricular extension and tentorial location. Mortality rate is high in patients presenting with higher ICH Scores. The intracerebral haemorrhage (ICH) score allows for a standardised and consistent clinical grading scale for ICH, thus improving communication among clinicians and hence this study was conducted to define a clinical grading scale for patients with ICH, that uses factors which are predictive of consequence and that can be readily \& precisely used at time of presentation, especially by a personnel with no specific training in stroke neurology. 4

\section{Objectives}

This study was conducted to know the aetiological and clinical profile in stroke patients with special reference to baseline ICH score in haemorrhagic stroke in North East India.

\section{METHODS}

This is a hospital based cross-sectional study conducted in the Department of Medicine at Assam Medical College and Hospital, Dibrugarh, in North East India. We enrolled patients from inpatient setting in this study. The study was approved by the ethical committee of Assam Medical College and Hospital, Dibrugarh. We obtained a written informed consent from all study participants before enrolling them in the study.

\section{Sample Size}

Based on proportion of risk factors by the study done by Eapen $\mathrm{R} P$ et al. ${ }^{2}$ A study of clinical profile and risk factors of cerebrovascular stroke, in 2009, with $95 \%$ confidence level and relative precision of $20 \%$ and after rounding up, the calculated sample size was 112 for our study.

A total of 112 patients who presented with symptoms suggestive of stroke to Assam Medical College and Hospital, between March 2019 and February 2020 were assessed for the relative frequency of ischemic, cardio-embolic and haemorrhagic stroke separately.

Stroke is defined as "an abrupt onset of a neurologic deficit that is attributable to a focal neurological cause". ${ }^{5}$ Stroke has occurred if the neurologic signs and symptoms persists beyond 24 hours or brain infarction is demonstrated.

A Special importance was given to tea garden workers presenting with symptoms of stroke who form significant proportion of case load in our hospital.

\section{Inclusion Criteria}

The following criteria were included in the study:

1. Patients above the age of 18 years.

2. All Patients with clinical and computed tomography (CT) confirmed diagnosis of stroke.

\section{Exclusion Criteria}

Patients with the following criteria were excluded from the study:

1. Patients below 18.

2. Stroke following head injury or space-occupying lesion (SOL).

3. Infarct with haematoma transformation.

4. Any bleeding diathesis.

5. Patients with no CT evidence to confirm diagnosis.

All patients included in the study after getting consent were taken with a detailed history regarding age, sex, occupation, time of occurrence of the event and co-morbid factors such as pre-existing diabetes, hypertension, cardiac disorders, renal failure, dyslipidaemia and drug intake including alcohol. A detailed history on smoking was obtained by smoking pack years. The patients were clinically assessed 
for vital parameters and detailed neurological examination and examination of other systems were conducted. Concurrently, the patients were also worked up for complete haemogram, coagulation profile and basic biochemical parameters including random blood sugar and renal / lipid profile / electrolyte profile, urine albumin / sugar / deposits, electrocardiogram (ECG), chest x-ray and CT brain. In needed cases, collagen vascular disease profile was done. All these parameters were collected by detailed history as with patients / attenders as appropriate in a standard hospital approved proforma. Glasgow Coma Scale (GCS) score at the time of admission, presence / absence of intraventricular extension of bleeding and ICH volume were documented.

\section{Statistical Analysis}

Data was entered into computer Microsoft Excel and exported to Statistical Package for the Social Sciences (SPSS) version 20 for analysis. Continuous variables were expressed as mean \pm standard deviation. Categorical variables were expressed as frequency and percentage. The chi-square test (for $2 \times 2$ tables) was used as test of significance for qualitative data. Pvalue was considered statistically significant when it was less than 0.05 .

\section{RESULTS}

In our study, it was found that the mean age for stroke was 57 years. 6,7 The stroke prevalence was maximum in $40-60$ years of the age group which comprises $50 \%$ of total patients [Figure 1]. Stroke was more common in males with a sex ratio of $1.24: 1$

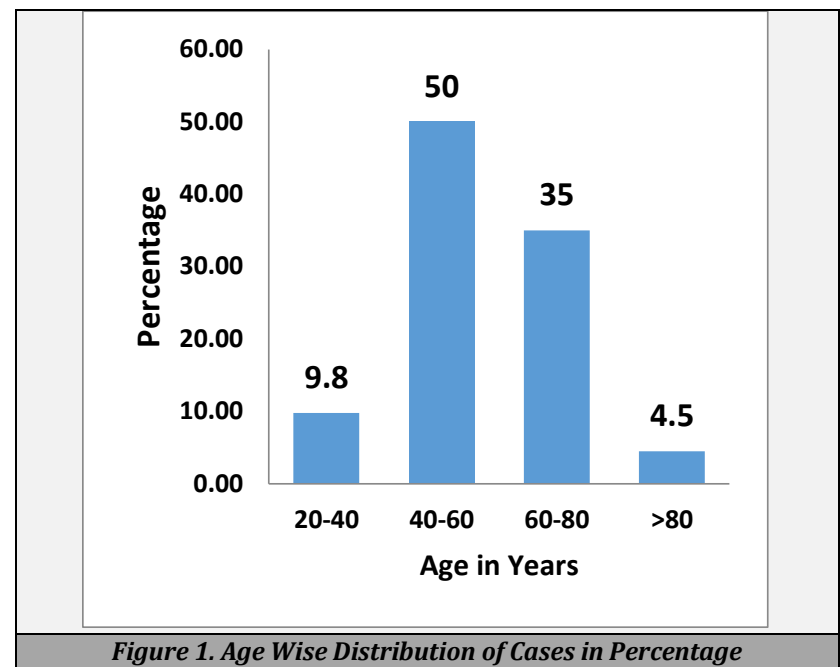

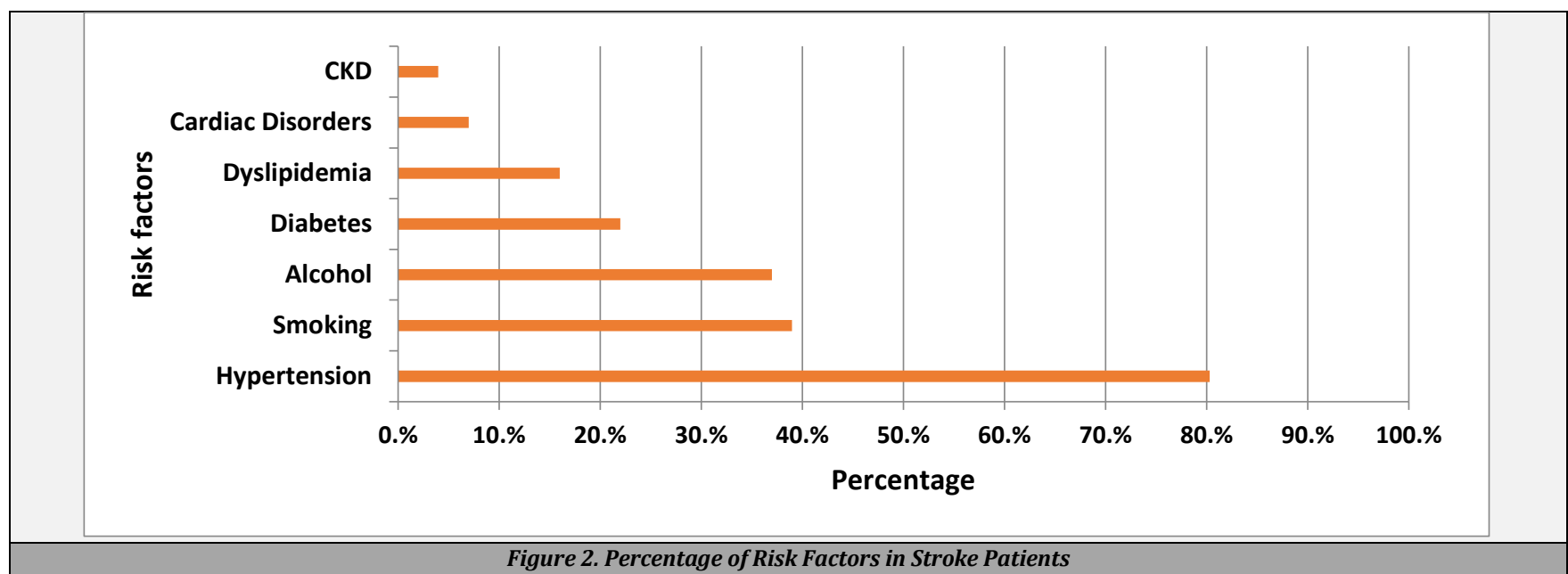

\begin{tabular}{|c|c|c|c|c|}
\hline & Variables & $\begin{array}{l}\text { Total No. of } \\
\text { Patients }\end{array}$ & $\begin{array}{l}\text { No. of Patients } \\
\text { Expired }\end{array}$ & $\begin{array}{c}\text { Mortality } \\
\text { Rate }\end{array}$ \\
\hline Association of GCS & $3-4$ & 15 & 15 & $100 \%$ \\
\hline \multirow{2}{*}{$\begin{array}{l}\text { Score at the time of } \\
\text { admission with } \\
\text { outcome }\end{array}$} & $5-12$ & 84 & 24 & $28.6 \%$ \\
\hline & $13-15$ & 13 & 0 & $0 \%$ \\
\hline \multirow{2}{*}{$\begin{array}{l}\text { Association of ICH } \\
\text { volume with } \\
\text { outcome }\end{array}$} & $>30 \mathrm{~cm}^{3}$ & 35 & 27 & $77 \%$ \\
\hline & $<30 \mathrm{~cm}^{3}$ & 47 & 6 & $12 \%$ \\
\hline \multirow{2}{*}{$\begin{array}{l}\text { Association of } \\
\text { intraventricular } \\
\text { extension with } \\
\text { outcome }\end{array}$} & Yes & 22 & 18 & $81 \%$ \\
\hline & No & 60 & 15 & $25 \%$ \\
\hline \multirow{2}{*}{$\begin{array}{l}\text { Association of } \\
\text { tentorial location } \\
\text { with outcome }\end{array}$} & Supratentorial & 58 & 18 & $31 \%$ \\
\hline & Infratentorial & 24 & 15 & $62 \%$ \\
\hline
\end{tabular}

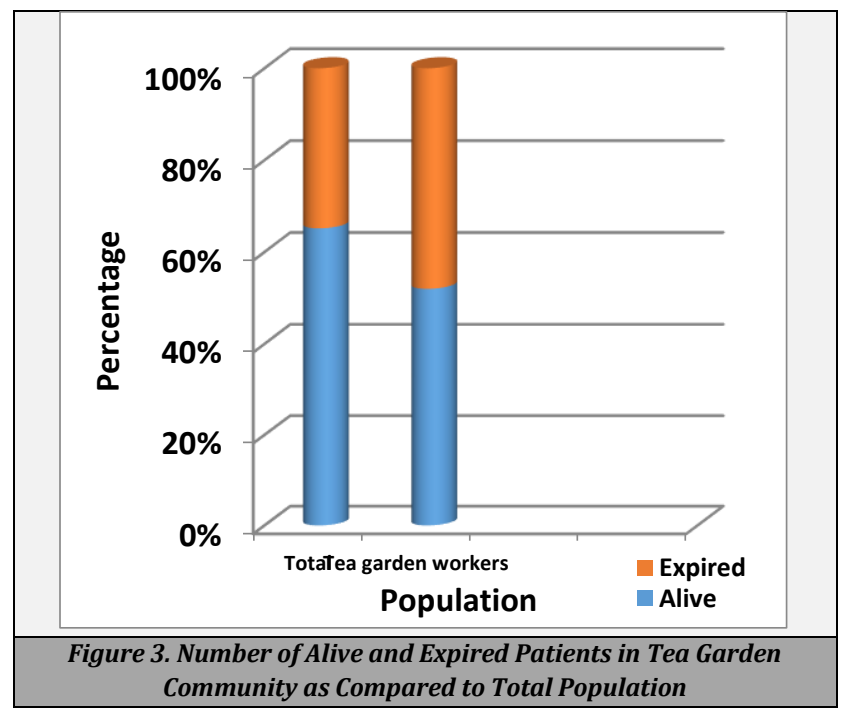




\begin{tabular}{|ccccc|}
\hline ICH Score & $\begin{array}{c}\text { Total No. of } \\
\text { Patients }\end{array}$ & Alive & $\begin{array}{c}\text { No. of Patients } \\
\text { Expired }\end{array}$ & $\begin{array}{c}\text { Mortality } \\
\text { Rate }\end{array}$ \\
0 & 3 & 3 & 0 & $0 \%$ \\
1 & 35 & 31 & 4 & $11.4 \%$ \\
2 & 16 & 9 & 7 & $43.7 \%$ \\
3 & 15 & 5 & 10 & $66.7 \%$ \\
4 & 7 & 1 & 6 & $85 \%$ \\
5 & 6 & 0 & 6 & $100 \%$ \\
6 & 0 & 0 & 0 & 0 \\
\hline \multicolumn{5}{c}{ Table 2. Association of ICH Score with Outcome } \\
\hline
\end{tabular}

From the Figure 2, we can see that hypertension was the most prevalent and an important risk factor for stroke 90 patients) with $80.3 \%$, followed by diabetes mellitus (25 patients) with $22 \%$ and dyslipidaemia (18 patients) with 16 $\%$. Also $7 \%$ of patients with cardiac disorders (8 patients), 4 $\%$ of patients with chronic kidney disease (5 patients), $39 \%$ smoker (44 patients) and $37 \%$ chronic alcoholic (42 patients $)^{8}$ suffered from stroke.

Mortality rate in stroke patients of tea garden working community is $48 \%$, which is significantly higher than the mortality rate in general population which is $34 \%$.

In our study, the most common site of haemorrhage was basal ganglia with 23 patients ( $28 \%$ ) followed by thalamus with 20 patients (24\%). This was followed by pons (13\%), cerebellum (7\%) and others. The above table shows patients presenting with low GCS score at the time of presentation, ICH volume > $30 \mathrm{~cm}^{3}$, presence of intraventricular extension and infratentorial location have high incidence of mortality. Patients having high ICH score at the time of presentation have high mortality.

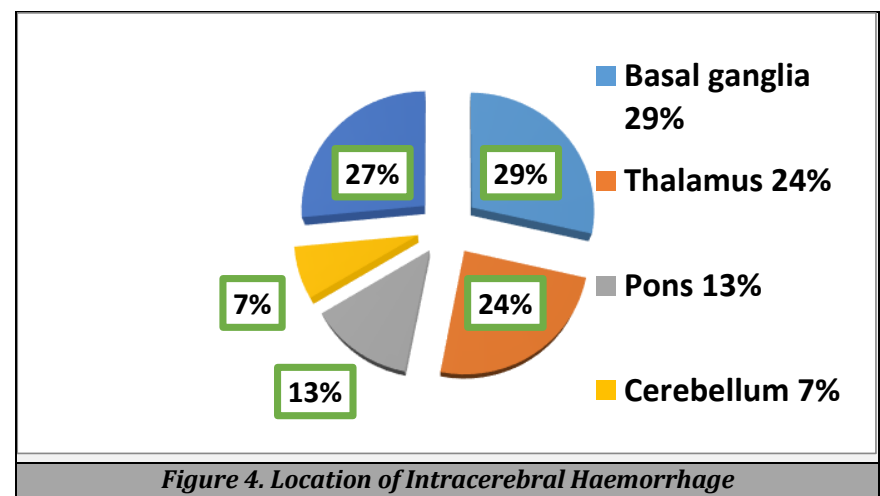

DISCUSSION

The effects of stroke can vary depending upon the area of the brain involved and the extent of the damage. The incidence of stroke increases with advancing age. Hypertension, diabetes mellitus, low normal haemoglobin and tobacco use (smoking / chewing) are the most prevalent and important risk factors for stroke. ${ }^{9}$ Stroke ranks first among all central nervous system diseases both in frequency and gravity. ${ }^{10}$ A clinical grading scale which is reliable enough in the patient classification must be considered. It should be simple enough to be used by general physician without any significant special training in stroke neurology. The ICH score is a clinical grading scale consists of five factors such as GCS score, age, ICH volume, intraventricular extension and tentorial location. ${ }^{11}$

Mehndiratta et al. showed sex ratio of 1:08 in North India, whereas Y KingslyJaba Singh et al. demonstrated a ratio of 1.6:1 in South India which is similar to our study with a ratio of 1.2:1. The mean age of stroke patients in our study was 57.3 years, whereas in a study by Brett M. Kissela et al. in 2005, the mean age was 69.2 years. The study also hypothesised that stroke incidence in younger adults increased over time, most notably between 1999 and 2005.6,7 Our present study showed the incidence of smoking associated with stroke to be $39 \%(\mathrm{P}$ $=0.021$ ). In another study by Nagaraja et al. ${ }^{12}$ it was $15 \%$, Dalal et al. ${ }^{13}$ it was $40 \%$, Bogousslavsky et al. ${ }^{14}$ it was $36.6 \%$ and Alverez et al. ${ }^{15}$ it was $56 \%$. Our study has results coinciding with the study by Bogousslavsky et al. In the study of Nagaraja et al. the incidence of chronic alcohol consumption was $15 \%$, Alvarez et al. it was $37.8 \%$ and Dalal it was $40 \%$ whereas our present study had $37 \%(\mathrm{P}=0.028)$.

In our present study, $80.3 \%$ of patients had hypertension ${ }^{16}$ and in other study by Dalal et al. showed an incidence of $46.7 \%$ and Alvarez et al. it was $23 \%$ and Nagaraja et al. it was $22.6 \%$. The incidence is much higher in our study probably because of high salt intake in this region $(\mathrm{P}=0.001)$. In the study by Dalal et al. the incidence of diabetes was $20 \%$, whereas study by Nagaraja et al. it was $11 \%$, Grindal et al. ${ }^{17}$ it was $5.2 \%$ and Alvarez et al. it was $10.9 \%$, whereas in our study, it was $22 \%$. Our study shows that the mortality rate in patients of tea garden workers (48\%) was much higher than the general population (34\%). This is mainly because of high prevalence of anaemia, increased salt intake and increased working hours, lack of access to basic healthcare and weak economic condition. ${ }^{18}$

In the present study, the incidence of haemorrhagic stroke was more with $73.2 \%$ followed by ischemic stroke which was $22.3 \%$, whereas in a study done by Aiyar et al. the incidence of ischemic stroke was $70 \%$, in Eapen et al. it was $68 \%$ and in a study in South India by Y Kingsly Jebasingh et al. it was $68.6 \%$. This is mainly because our institution being the only tertiary care centre in this part of country has more referral cases of haemorrhagic stroke than the ischemic stroke. In our study, the most common site of haemorrhage was basal ganglia in 23 patients (28\%) followed by thalamus in 20 patients $(24 \%)$. This was followed by pons (13\%), cerebellum (7\%) and others. A study done by Y Kingsly Jebasingh et al. showed that the capsule-ganglionic was the commonest location involved (20.71\%), followed by parietal (9.28\%), cerebellar (8.57\%) and frontal lobe $(5.71 \%)$. A clinical grading scale (ICH score) was developed for all patients presenting with haemorrhagic stroke. Patients having high ICH score at the time of presentation had high mortality. In our study, patients presenting with high ICH score $(\geq 3)$ had high mortality whereas those with low ICH score $(<3)$ had low mortality $(\mathrm{P}=$ 0.010). Out of five parameters to calculate ICH Score, "GCS" had strong association with the outcome. A study by J. Claude Hemphill et al. showed 34 of 35 patients with a presenting GCS score of $(<4)$ died and 5 of 60 patients with a presenting GCS score (13 to 15) died and 29 of 57 patients with GCS score (5 to 12$)$ died whereas in our study, 15 of 15 patients with a GCS score (<4) died, 24 of 84 patients with a GCS score (5 to 12) died and all patients with GCS score (13 to 15$)$ survived.

\section{CONCLUSIONS}

We have found a higher number of haemorrhagic strokes $(73.2$ $\%)$. Hypertension $(80.3 \%)$ is the most prevalent and an 
important risk factor followed by chronic alcohol consumption (39\%), smoking (37\%) and diabetes (22\%). Basal ganglia (28 $\%)$ are the most common sites involved in haemorrhagic stroke; infratentorial location is associated with poor prognosis. Patients presenting with low GCS score $(<4)$ at the presentation and having high ICH score $(\geq 3)$ have been associated with increased mortality.

Data sharing statement provided by the authors is available with the full text of this article at jemds.com.

Financial or other competing interests: None.

Disclosure forms provided by the authors are available with the full text of this article at jemds.com.

We would like to thank Dr. Chayanika Dutta, Dr. Sarat Chandra Hazarika, Dr Ramanan B B V, Dr Arijit Das, Dr Sanchu TK Sreeraj and Angshuman Boruah, statistician from the Department of Medicine, Unit 5, Assam Medical College and Hospital, for their help during the study.

\section{REFERENCES}

[1] Mackay J, Mensah GA. Atlas of heart disease and stroke: Global Burden of Stroke. Geneva: World Health Organisation 2004.

[2] Eapen RP, Parikh JH, Patel NT. A study of clinical profile and risk factors of cerebrovascular stroke. Guj Med J 2009;64(2):47-54.

[3] Bath P. Acute stroke. In: Machin D, Day S, Green S, eds. Textbook of Clinical trials. $2^{\text {nd }}$ edn. Hoboken: Wiley 2006:179-80.

[4] Cheung RTF, Zou LY. Use of the original, modified or new intracerebral hemorrhage score to predict mortality and morbidity after intracerebral haemorrhage. Stroke 2003;34(7);1717-22.

[5] Smith WS, Johnston SC, Hemphill JC. Cerebrovascular diseases. In: Harrison's Principles of Internal Medicine. 20th edn. Philadelphia: McGraw-Hill Education 2018: p. 3068.
[6] Pandian JD, Sudhan P. Stroke epidemiology and stroke care services in India. J Stroke 2013;15(3):128-34.

[7] Kasper D, Fauci A, Hauser S, et al. Cerebrovascular Diseases. In: Harrison's Principles of Internal Medicine. New York: McGraw-Hill Education 2015: p. 2559.

[8] Dalal PM, Dalal KP, Rao SV, et al. Neurology in Europe. In: Bartko D, edr. Strokes in west-central India: a prospective case-control study of risk factors (a problem of developing countries). London: John Libbey \& Co. Ltd., 1989: p. 16-20.

[9] Dalal PM. Stroke in India: issues in primary and secondary prevention. Neurology India 2002;50(Suppl 1):S2-S7.

[10] Dalal PM. Burden of stroke: Indian perspective. Int J Stroke 2006;1(3):164-6.

[11] Hemphill JC, Bonovich DC, Besmertis L, et al. The ICH score: a simple, reliable grading scale for intracerebral hemorrhage. Stroke 2001;32(4):891-7.

[12] Nagaraja D, Gurumurthy SG, Taly AB, et al. Risk factors for stroke: relative risk in young and elderly. Neurol India 1998;46(2):183-4.

[13] Dalal PM. Strokes in young and elderly: risk factors and strategies for stroke prevention. J Assoc Physic India 1997;45:125-31.

[14] Bogousslavsky J, Pierre P. Ischemic stroke in patients under age 45. Neurol Clin 1992;10(1):113-24.

[15] Alvarez J, Matias-Guiu J, Sumalla J, et al. Ischemic stroke in young adults. I. Analysis of the etiological subgroups. Acta Neurol Scand 1989;80(1):28-34.

[16] Brott T, Thalinger K, Hertzberg V. Hypertension as a risk factor for spontaneous intracerebral hemorrhage. Stroke 1986;17(6):1078-83.

[17] Grindal AB, Cohen RJ, Saul RF, et al. Cerebral infarction in young adults. Stroke 1978;9(1):39-42.

[18] Medhi GK, Hazarika NC, Shah B, et al. Study of health problems and nutritional status of tea garden population of Assam. Indian J Med Sci 2006;60(12):496-505. 